\title{
Physical illness associated with depression in the elderly in community based and hospital patients
}

\author{
StePhen Dover, Registrar in Psychiatry, Bradwell Hospital, Chesteron, Staffs ST5 7NJ; \\ and Christopher McWilliam, Senior Lecturer in Psychiatry, University of Keele
}

The co-existence of physical and psychiatric illness in so much of the elderly population poses diagnostic and therapeutic problems for psychiatrists, geriatricians and general practitioners alike, with the presence of physical illness strongly influencing and sometimes limiting the options for treatment of the psychiatric illness. Recognition of this has resulted in the Section of Old Age Psychiatry of the Royal College of Psychiatrists recommending that senior registrar training in old age psychiatry should include a one month attachment to an approved geriatric medicine unit.

\section{The study}

This study demonstrates high levels of physical illness in elderly depressive patients both in hospital and in the community and reinforces the importance of this higher training requirement.

A retrospective and continuing process audit of all referrals (100) for 'depression' to a psychogeriatric service for some 18,000 elderly subjects was undertaken over 30 months. Each patient was classified into one of three categories for depression according to DSM-III-R and significant physical illness and all medication recorded.

\section{Findings}

The sample consisted of 31 males and 69 females. The age range for males was 67-97 (mean 77.4) years and for females 65-94 (mean 68.3). This difference was statistically significant ( $\chi^{2}$ test $\left.P<0.001\right)$. Thirtytwo per cent of males and $42 \%$ of females were in diagnostic category 1 (dysthymia and uncomplicated bereavement). Forty-two per cent of males and 39\% of females in category 2 (major depression and bipolar disorder) and $26 \%$ of males and $19 \%$ of females in category 3 (alcohol abuse, personality disorder and dementia with depression). Three patients, all male, were found not to be depressed and are excluded.

Physical illness in the sample is documented in Table 1.

Only $8 \%$ of the men and $20 \%$ of the women in the sample had no significant physical illness. There was
TABLE I.

This table shows the distribution of physical illness for each sex

\begin{tabular}{lrrrr}
\hline & \multicolumn{3}{c}{ Male } & \multicolumn{2}{c}{ Female } \\
\cline { 2 - 5 } Diagnosis & No. & $\%$ & No. & $\%$ \\
\hline Well & 3 & 8 & 12 & 20 \\
Cardiovascular & 23 & 64 & 29 & 48 \\
Cerebrovascular & 6 & 17 & 8 & 13 \\
Malignancy & 3 & 8 & 8 & 13 \\
Diabetes & 2 & 6 & 3 & 5 \\
Arthritis & 8 & 22 & 11 & 18 \\
Prostatic hypertrophy & 9 & 25 & \multicolumn{2}{c}{ N/A } \\
Respiratory & 9 & 25 & 2 & 3 \\
Deafness & 5 & 14 & 9 & 15 \\
Visual impairment & 6 & 17 & 8 & 13 \\
$\quad$ (including glaucoma) & \multicolumn{2}{c}{8} \\
Multiple illness & 23 & 64 & 40 & 66 \\
\hline
\end{tabular}

no significant difference in disease pattern between males and females or between diagnostic groups. Cardiovascular illness was prominent in both sexes and multiple pathology was common, with $64 \%$ of the males and $66 \%$ of the females so affected.

\section{Cardiovascular disease}

The main diagnoses in the group were hypertension and congestive cardiac failure. Of the sample, $57 \%$ were receiving treatment for these, with diuretics or beta blockers the most commonly prescribed drugs among the sample as a whole. Thirty-nine per cent of the sample were receiving multiple therapy for cardiovascular disorders.

\section{Cerebrovascular disease}

The majority of the patients in this category had a history of cerebrovascular accident resulting in loss of physical function with reduction in mobility and speech impairment predominant.

\section{Malignancy}

Two male and eight female patients were known cases of carcinoma at the time of referral and were 
referred because of superimposed depression. One man with carcinoma of bladder, one woman with uterine carcinoma and one with large bowel carcinoma were previously undiagnosed and discovered during assessment for their depressive illness in hospital.

\section{Prostatic hypertrophy}

This was recorded specifically because of the implications for choice of antidepressent medication. Thirty-one per cent of the males tested had symptoms of prostatic enlargement or had enlarged prostates on rectal examination. Four of these patients had prostatectomies during their period of illness and six more are currently awaiting surgery.

\section{Multiple illness}

Multiple illness was the rule rather than the exception. Males tended to have cardiac, cerebrovascular and respiratory disorders and females cardiac and cerebrovascular disorder. Both groups often had additional problems with arthritis and sensory deficits. Multiple illness was reflected in the patterns of drug treatment; only $26 \%$ of men and $16 \%$ of women were receiving no medication, with $40 \%$ of men and $60 \%$ of women taking more than two drugs on referral. Of the patients taking medication for physical illness, $67 \%$ of women and $54 \%$ of men were taking at least one form of psychotropic medication in addition.

\section{Death}

Three patients, two male and one female, died during the course of the study. One man died from carcinoma and one man and one woman died following cerebrovascular accidents.

\section{Comment}

Chronic ill health is common among the elderly population and the prevalence of both physical and psychiatric disorders increases rapidly with age. This has been shown to be of importance in long-stay hospital patients (Stewart, 1991) and our study demonstrates the strong association between physical illness and depression in elderly patients both in hospital and in the community.
The association with depressive illness is particularly important as depression may arise through the individual's interpretation of physical illness (Brown \& Harris, 1978), as a direct result of organic disease (Starkstein \& Robinson, 1989) or as a result of the treatment of physical illness (Smythe, 1982).

Although only one patient in the sample could be said to have been suffering from "iatrogenic" depression (a male receiving treatment with L-dopa), a large percentage of patients were receiving treatment with potentially "depressogenic" medication which may have contributed to their symptomatology.

The presence of such a high level of physical illness in depressed subjects has important implications for their pharmacological management, especially for those treated outside hospital. Elderly patients metabolise and eliminate antidepressants more slowly, are much more susceptible to adverse reactions and tolerate side effects less well. High rates of cardiovascular disorders, glaucoma and prostate disease and associated polypharmacy have an important influence on the potential toxicity of antidepressants and may also effect compliance with treatment and ultimately efficacy. Furthermore admission to hospital may be required for treatment of relatively minor depressive disorders because of the coincidence of physical illness.

This study and that of Stewart (1991) highlight the need for a thorough working knowledge of geriatric medicine and therapeutics in relation to psychogeriatrics especially for those patients treated in long stay facilities or in the community where there is often limited access to specialist medical advice. We therefore welcome the introduction of the secondment period in geriatric medicine as a requirement for senior registrar training.

\section{References}

Brown, G. W. \& Harris, T. O. (1978) Social Origins of Depression. London: Tavistock.

SMYTHE, J. T. (1982) latrogenic disease in the elderly. Australian Family Physician, 11, 785-788.

Starkstein, S. E. \& Robinson, R. G. (1989) Affective disorders and cerebral vascular disease. British Journal of Psychiatry, 154, 170-182.

STEWART, M. (1991) The physical health of old long stay in-patients in one psychiatric hospital. Psychiatric Bulletin, 15, 404-406. 